\title{
Long-Term Effects of a Losartan- Compared With an Atenolol-Based Treatment Regimen on Carotid Artery Plaque Development in Hypertensive Patients With Left Ventricular Hypertrophy: ICARUS, a LIFE Substudy
}

\author{
Eigil Fossum, MD, PhD; ${ }^{1}$ Michael Hecht Olsen, MD, PhD ${ }^{3}$ Aud Høieggen, MD, PhD ${ }^{2}$ \\ Kristian Wachtell, MD, $\mathrm{PhD} ;{ }^{4}$ Henrik M. Reims, MD, $\mathrm{PhD} ;{ }^{1}$ Sverre E. Kjeldsen, MD, PhD; ${ }^{1,5}$ \\ Hans Ibsen, MD, PhD; ${ }^{4}$ Ying Wan, MD, MS; ${ }^{5}$ Stevo Julius, MD, ScD 6
}

In the Losartan Intervention for Endpoint Reduction in Hypertension (LIFE) study, there was a 25\% risk reduction for stroke with angiotensin receptor blocker-based therapy (losartan) as compared with $\beta$ blocker-based therapy (atenolol) despite comparable blood pressure reductions. This substudy examines treatment effects on the amount and density of atherosclerotic lesions in the common carotid arteries and the carotid bulb in 81 patients during 3 years of treatment. There were no statistically significant changes in the amount of carotid plaque in patients treated with losartan compared with an atenololbased treatment program. A statistically nonsignifi-

From the Departments of Cardiology $y^{1}$ and Nephrology, ${ }^{2}$ Ullevaal University Hospital, Oslo, Norway; the Departments of Clinical Physiology and Nuclear Medicine ${ }^{3}$ and Internal Medicine, ${ }^{4}$ Glostrup University Hospital, Glostrup, Denmark; Merck Research Laboratories, Blue Bell, PA; ${ }^{5}$ and the Division of Hypertension, Department of Internal Medicine, University of Michigan Medical Center, Ann Arbor, $M I^{6}$

Address for correspondence:

Eigil Fossum, MD, PhD, Department of Cardiology, Ullevaal University Hospital, N-0407 Oslo, Norway E-mail:eigil.fossum@medisin.uio.no

Manuscript received November 11, 2005; revised December 1, 2005; accepted December 6, 2005 cant increase in plaque density and index (average of plaque amount and density) was seen in the atenolol group compared with those treated with losartan. The small number of patients evaluated may have limited the power to detect a difference in outcome. The difference in carotid plaque index increase between the treatment groups during 3 years of treatment could not be statistically linked to specific treatments in the present substudy. (J Clin Hypertens.

2006;8:169-173) ${ }^{2} 2006$ Le Jacq Ltd.

$\mathrm{H}$ ypertension is a major risk factor for morbidity and mortality. ${ }^{1,2}$ Until 2002, no drug or drug class had shown superiority over another in reducing cardiovascular end points; i.e., all antihypertensive drugs reduced cardiovascular risk comparably. ${ }^{3}$ In the Losartan Intervention for Endpoint Reduction in Hypertension (LIFE) study, ${ }^{4}$ however, therapy based on the angiotensin receptor blocker (ARB) losartan reduced cardiovascular end points significantly better than therapy based on the $\beta$ blocker atenolol despite similar blood pressure $(\mathrm{BP})$ reductions in the treatment arms in 9193 patients with hypertension and left ventricular hypertrophy. More than $70 \%$ of patients in each group received a diuretic. One of the striking findings in the LIFE study was a $25 \%$ risk reduction for stroke in the losartan group. Because this difference appeared to be independent of BP, other mechanisms were considered. We have 
previously investigated possible mechanisms that could explain this difference in stroke risk, such as hyperinsulinemia and intima-media thickness of the carotid arteries. $^{5-7}$

Atherosclerotic plaques in carotid arteries are associated with an increased risk of stroke, probably because they are markers of generalized atherosclerosis as well as sources of thromboembolism. ${ }^{8}$ Angiotensin II is likely to be involved in atherogenesis by enhancement of endothelial dysfunction, vascular low-density lipoprotein oxidation, adhesion molecule expression, and up-regulation of cytokine expression. ${ }^{9}$ Losartan, an angiotensin II type 1 receptor antagonist, may prevent atherosclerosis in animal models, ${ }^{10}$ and has been shown to correct small artery structural changes and normalize endothelial function in humans, while atenolol had no such effects in humans despite similar lowering of BP. ${ }^{11}$ On the other hand, $\beta$ blockers may also have antiatherosclerotic effects. ${ }^{12}$ There are, however, only limited observations on the effects of antihypertensive drugs on carotid atherosclerotic plaque formation in humans. In the present analyses from the LIFE Insulin Carotids US Scandinavia (ICARUS) substudy, we tested the hypothesis that losartan is superior to atenolol in inhibition of carotid artery plaque formation.

\section{METHODS}

\section{Subjects}

According to a prespecified protocol in the LIFE study, ${ }^{4} 99$ patients with essential hypertension and left ventricular hypertrophy were included in the ICARUS substudy. ${ }^{5}$ They met the LIFE inclusion and exclusion criteria, ${ }^{4}$ and were evaluated at study baseline (after 2 weeks of placebo treatment), and after 1, 2, and 3 years of study treatment. Baseline characteristics of ICARUS substudy patients have been published previously. ${ }^{5}$ In the present analyses, four patients had no or inadequate ultrasound readings at baseline, and 14 patients had no readings during follow-up, leaving 81 patients in the present study. Similar numbers of patients were randomized to the two study drugs, and baseline characteristics were similar in the groups (Table I). Patients included in the present study were from the centers at Glostrup, Copenhagen, and Ullevaal, Oslo. All patients provided written informed consent, and the substudy protocol was approved by all relevant ethics committees.

\section{Carotid Plaque Measurements}

The amount and density of atherosclerotic lesions were semiquantitatively assessed in the common carotid arteries and in the carotid bulb based on bilateral ultrasound images; i.e., a total of four segments in each patient. We used the ACUSON 128XP/10c (Acuson Corporation, Mountain View, CA) and a linear 7-MHz transducer (L7). Measurements were made in the $1-\mathrm{cm}$ segment proximal to the dilation of the carotid bulb as described by Howard et al., ${ }^{13}$ and in the carotid bulb. In the common carotid arteries and in the carotid bulb, we semiquantitatively assessed the amount of atherosclerotic lesions $(0=$ none, $0.5=$ very few, $1=$ few, $1.5=$ some, 2 = several) and the density (shadow) of atherosclerotic lesions $(0=$ no, $0.5=$ very little, $1=$ little, $1.5=$ some, 2 = full). Plaque index was calculated as the average of the amount and density scores. All assessments were made from digital images by the same technician, who was blinded to the patients' treatment allocations.

\section{BP Measurements}

According to the LIFE study protocol, sitting BP was measured with a manual mercury sphygmomanometer. In this substudy, resting BP was also measured at baseline and during follow-up with the patient in the supine position using a manual mercury sphygmomanometer or a semiautomatic sphygmomanometer (Dinamap Model 1846 SX, Critikon, Johnson \& Johnson Medical, Inc., New Brunswick, NJ). BPs measured at Years 1, 2, and 3 were averaged. Sitting and supine BP levels were comparable in patients recruited at different centers.

\section{Statistics}

Data were analyzed with SPSS version 11.0 for Windows (SPSS Inc., Chicago, IL). The mixed models were analyzed with SAS version 8.2 (SAS Institute Inc., Cary, NC). For comparison between treatment groups, Student's independent samples $t$ test was used for normally distributed data. The MannWhitney test was used for skewed data. Differences in distribution of gender and smoking (Table I) were tested with the chi-square test. The annual changes in amount/density of plaque were compared between the two treatments by analysis of variance. Additional analysis of variance models included baseline measurement as a covariate. To investigate the overall effect of treatment on amount/density of plaque over time, a mixed model with repeated measures was used. The dataset for this model consisted of multiple measurements of amount/density of plaque over time (Years 1-3) for each patient. The model was fitted by treatment, and with/without baseline measurements were covariates. Null hypotheses were rejected if two-tailed $p<0.05$. 


\section{RESULTS}

Demographic variables, BP, and heart rate were comparable in the two groups at baseline (Table I). Compared with baseline, systolic and diastolic BPs were significantly lower $(p<0.0005$ for all $)$ at Years 1-3 in both groups, but there were no significant differences between the groups at any time. Compared with baseline, heart rate was significantly lower at Years 1-3 in the atenolol group ( $p<0.001$ for all), but not in the losartan group. Body mass index did not differ significantly between the groups during follow-up.

Carotid plaque amount and density in the two groups at baseline and during 3 years of treatment are shown in Table II. There was a $12 \%$ difference in plaque amount between the two groups at baseline. Carotid index (average of amount and density) is also shown in Table II. The amount of plaque decreased in patients treated with losartan, while it increased in those treated with atenolol, but the differences were not statistically significant: -0.024 vs. $0.098 ; p=0.375$ (unadjusted) and $p=0.471$ (adjusted for baseline variables). Patients treated with atenolol had a greater increase in plaque index than those treated with losartan, (0.123 compared with 0.049$)$. To test whether there was a significant treatment difference in plaque index over time, a longitudinal mixed model with repeated measures in which the dataset consisted of multiple measurements of plaque over time (Years 1-3) for each patient was applied. The test showed $p=0.655$ for the unadjusted longitudinal model, and $p=0.742$ for the longitudinal model adjusted for baseline measurements. Thus, the difference in carotid plaque index between losartan and atenolol during 3 years of treatment was also not statistically significant.

\section{DISCUSSION}

In the present study, the amount and density of carotid plaques and carotid plaque index (the average of plaque amount and density) were assessed at baseline and during three years of treatment in a cohort of LIFE participants treated with a regimen based on the ARB losartan compared with the $\beta$ blocker atenolol. BP was significantly and comparably reduced in the two groups. A nonsignificant change in the amount of plaque between patients receiving the ARB and the $\beta$ blocker was noted. There was a numeric increase in plaque index in both groups during 3 years of treatment. No statistically significant difference was noted on the different treatment regimens.

The $25 \%$ reduction of stroke incidence in the losartan arm of the LIFE trial appeared to have been

\begin{tabular}{|c|c|c|}
\hline VARIABLE & $\begin{array}{l}\text { LOSARTAN } \\
(\mathrm{N}=39)\end{array}$ & $\begin{array}{c}\text { AtenOLOL } \\
(\mathrm{N}=42)\end{array}$ \\
\hline Age (yr) & $67(7)$ & $67(6)$ \\
\hline Men/women (n) & $27 / 12$ & $31 / 11$ \\
\hline Smoker/ex-smoker/never smoked (n)* & $7 / 16 / 14$ & $3 / 18 / 16$ \\
\hline Body mass index $\left(\mathrm{kg} / \mathrm{m}^{2}\right)$ & $28.3(3.1)$ & $27.3(3.4)$ \\
\hline Total cholesterol (mmol/L) & $6.0(1.1)$ & $6.2(1.1)$ \\
\hline HDL cholesterol (mmol/L) & $1.4(0.4)$ & $1.5(0.4)$ \\
\hline Glucose $(\mathrm{mmol} / \mathrm{L})$ & $5.9(1.4)$ & $5.8(1.4)$ \\
\hline Insulin $(\mathrm{pmol} / \mathrm{L})$ & $48(26)$ & $48(21)$ \\
\hline Systolic blood pressure (mm Hg) & $173(18)$ & $169(16)$ \\
\hline Diastolic blood pressure $(\mathrm{mm} \mathrm{Hg})$ & $97(12)$ & $93(8)$ \\
\hline Heart rate $(\mathrm{bpm})$ & $68(10)$ & $69(11)$ \\
\hline \multicolumn{3}{|c|}{$\begin{array}{l}\text { Values are mean (SD) unless otherwise indicated. No significant } \\
\text { differences were found between the two groups. HDL=high- } \\
\text { density lipoprotein; *smoking data missing for two subjects in } \\
\text { the losartan group and five subjects in the atenolol group }\end{array}$} \\
\hline
\end{tabular}

achieved independently of BP changes. Thus, other mechanisms may be involved. From a pathophysiologic point of view, it is reasonable to investigate possible treatment effects on the carotid arteries. Antihypertensive treatment with losartan has been shown to improve vascular structure by reduction of the media-lumen ratio of resistance vessels, ${ }^{11}$ and to improve arterial function in hypertensives. ${ }^{14}$ This medication may also prevent atherosclerosis in animal models. ${ }^{10}$ Such effects may possibly be explained by inhibition of the production and release of inflammatory mediators. ${ }^{15,16}$ There are, however, limited observations of the effects on carotid atherosclerotic plaque formation in humans. On the other hand, it has also been reported that $\beta$ blockers may have an antiatherosclerotic effect in carotid arteries. ${ }^{12}$ The carotid plaque index increased 0.049 and 0.123 from baseline to Year 3 in the losartan and atenolol groups, respectively, but the difference was not significant. If the difference in plaque index is a real one, one would probably need at least a 10 -fold sample size compared with the present study to have the power to show a significant difference. When this study was designed, there were no relevant data to suggest the magnitude of effect and thus an accurate sample size. Thus, it is difficult to judge whether there is a type 2 error, or whether there were truly no clinically relevant differences between the drugs regarding plaque development.

In the present study, we used a semiquantitative method to assess plaque amount and density. As atherosclerosis is a focal phenomenon, assessment of plaque amount and density may offer advantages compared with assessment of intima-media 


\begin{tabular}{|c|c|c|c|c|c|c|c|c|c|c|}
\hline \multirow[b]{2}{*}{ Parameter } & \multicolumn{4}{|c|}{ LOSARTAN $(\mathrm{N}=39)$} & \multicolumn{4}{|c|}{ Atenolol $(\mathrm{N}=42)$} & \multicolumn{2}{|r|}{$P$ VAlue } \\
\hline & $\mathrm{N}$ & PrE & Post & Change & $\mathrm{N}$ & PRE & Post & Change & ANOVA* & ANOVA** $^{* *}$ \\
\hline \multicolumn{11}{|l|}{ AMOUnt } \\
\hline Year 1 & 39 & 0.972 & 0.968 & -0.003 & 42 & 0.855 & 0.888 & 0.033 & 0.675 & 0.905 \\
\hline Year 2 & 32 & 0.973 & 0.879 & -0.094 & 40 & 0.839 & 0.923 & 0.084 & 0.037 & 0.071 \\
\hline Year 3 & 33 & 0.966 & 0.986 & 0.020 & 40 & 0.820 & 1.001 & 0.181 & 0.127 & 0.245 \\
\hline Over all years & 104 & 0.970 & 0.947 & -0.024 & 122 & 0.838 & 0.937 & 0.098 & $\begin{array}{c}\text { Mixed model } \\
0.375 \\
\end{array}$ & $\begin{array}{l}\text { Adjusted mixed model } l^{\dagger \dagger} \\
0.471\end{array}$ \\
\hline \multicolumn{11}{|l|}{ Density } \\
\hline Year 1 & 39 & 0.664 & 0.744 & 0.081 & 42 & 0.655 & 0.751 & 0.096 & 0.870 & 0.879 \\
\hline Year 2 & 32 & 0.699 & 0.782 & 0.083 & 40 & 0.622 & 0.789 & 0.167 & 0.385 & 0.436 \\
\hline Year 3 & 33 & 0.678 & 0.887 & 0.209 & 40 & 0.619 & 0.804 & 0.185 & 0.830 & 0.760 \\
\hline Over all years & 104 & 0.679 & 0.801 & 0.122 & 122 & 0.632 & 0.780 & 0.148 & $\begin{array}{c}\text { Mixed model }{ }^{\dagger} \\
0.951 \\
\end{array}$ & $\begin{array}{l}\text { Adjusted mixed model }{ }^{\dagger \dagger} \\
0.969\end{array}$ \\
\hline \multicolumn{11}{|c|}{ Index (Average of Amount and Density) } \\
\hline Year 1 & 39 & 0.819 & 0.857 & 0.038 & 42 & 0.756 & 0.820 & 0.064 & 0.711 & 0.813 \\
\hline Year 2 & 32 & 0.838 & 0.831 & -0.006 & 40 & 0.731 & 0.856 & 0.125 & 0.079 & 0.111 \\
\hline Year 3 & 33 & 0.824 & 0.938 & 0.114 & 40 & 0.720 & 0.902 & 0.182 & 0.475 & 0.603 \\
\hline Over all years & 104 & 0.826 & 0.875 & 0.049 & 122 & 0.736 & 0.859 & 0.123 & $\begin{array}{c}\text { Mixed model } \\
0.655 \\
\end{array}$ & $\begin{array}{c}\text { Adjusted mixed model }{ }^{\dagger \dagger} \\
0.742 \\
\end{array}$ \\
\hline $\begin{array}{l}\text { ANOVA=anal } \\
\text { model include } \\
\text { for each patien }\end{array}$ & . & iance; ${ }^{*} A$ & NOVA & model inc & ludes c & changes & as deper & dent varia & $\begin{array}{l}\text { e and treatment } \\
\text { neasures includes }\end{array}$ & $\begin{array}{l}\text { main effect; }{ }^{* *} \text { ANOVA } \\
\text { measurements of changes }\end{array}$ \\
\hline
\end{tabular}

thickness, as discussed by Spence. ${ }^{17}$ All readings were assessed by one single technician who was blinded to the patients' treatment allocations. The $12 \%$ difference between the groups in plaque amount at baseline was not statistically significant and could not be linked to differences in the baseline variables measured i.e., BP, age, smoking, or lipids. To correct for this difference, baseline measurements were included as a covariate in the analyses.

\section{CONCLUSION}

There was no significant difference between an ARB- and a $\beta$-blocker-based treatment regimen in carotid plaque index in hypertensive patients with left ventricular hypertrophy during 3 years of antihypertensive treatment with equivalent and significant reductions in BP. The findings in this study suggest a trend for a numeric increase in plaque index in the atenolol-treated patients. Further investigation of carotid plaque differences with various antihypertensive agents is indicated.

Acknowledgments and disclosure: We acknowledge the technical assistance of Lisa Krause in Ann Arbor, MI, Merete Molvig in Oslo, Norway, and Ingrid Emanuel in Copenhagen, Denmark. We thank Paulette A. Lyle for assistance with the manuscript. This research was supported in part by a grant from Merck \& Co., Inc., West Point, PA.

\section{REFERENCES}

1 Lewington S, Clarke R, Qizilbash $\mathrm{N}$, et al., for the Prospective Studies Collaboration. Age-specific relevance of usual blood pressure to vascular mortality: a meta-analysis of individual data for one million adults in 61 prospective studies. Lancet. 2002;360:1903-1913.

2 Ezzati M, Lopez AD, Rodgers A, et al., for the Comparative Risk Assessment Collaborating Group. Selected major risk factors and global and regional burden of disease. Lancet. 2002;360:1347-1360.

3 Kjeldsen SE, Westheim AS, Os I. INSIGHT and NORDIL. International Nifedipine GITS study: Intervention as a Goal in Hypertension Treatment. Nordic Diltiazem Study. Lancet. 2000;356:1929-1930.

4 Dahlöf B, Devereux RB, Kjeldsen SE, et al. Cardiovascular morbidity and mortality in the Losartan Intervention For Endpoint Reduction in Hypertension study (LIFE): a randomised trial against atenolol. Lancet. 2002;359:995-1003.

5 Olsen MH, Fossum E, Hjerkinn E, et al. Relative influence of insulin resistance versus blood pressure on vascular changes in longstanding hypertension. ICARUS, a LIFE substudy. Insulin Carotids US Scandinavia. I Hypertens. 2000;18:75-81.

6 Olsen MH, Fossum E, Høieggen A, et al. Long-term treatment with losartan versus atenolol improves insulin sensitivity in hypertension: ICARUS, a LIFE substudy. J Hypertens. 2005;23:891-898.

7 Olsen MH, Wachtell K, Neland K, et al. Losartan but not atenolol reduce carotid artery hypertrophy in essential hypertension. A LIFE substudy. Blood Press. 2005;14:177-183.

8 Hollander M, Bots ML, Del Sol AI, et al. Carotid plaques increase the risk of stroke and subtypes of cerebral infarction in asymptomatic elderly: the Rotterdam study. Circulation. 2002;105:2872-2877.

9 Brasier AR, Recinos A III, Eledrisi MS. Vascular inflammation and the renin-angiotensin system. Arterioscler Thromb Vasc Biol. 2002;22:1257-1266.

10 Sun YP, Zhu BQ, Browne AE, et al. Comparative effects of $\mathrm{ACE}$ inhibitors and an angiotensin receptor blocker on atherosclerosis and vascular function. J Cardiovasc Pharmacol Ther. 2001;6:175-181.

11 Schiffrin EL, Park JB, Intengan HD, et al. Correction of 
arterial structure and endothelial dysfunction in human essential hypertension by the angiotensin receptor antagonist losartan. Circulation. 2000;101:1653-1659.

12 Wiklund O, Hulthe J, Wikstrand J, et al. Effect of controlled release/extended release metoprolol on carotid intima-media thickness in patients with hypercholesterolemia: a 3-year randomized study. Stroke. 2002;33:572-577.

13 Howard G, Sharrett AR, Heiss G, et al. Carotid artery intimal-medial thickness distribution in general populations as evaluated by B-mode ultrasound. ARIC investigators. Stroke. 1993;24:1297-1304.

14 Klemsdal TO, Moan A, Kjeldsen SE. Effects of selective angiotensin II type 1 receptor blockade with losartan on arterial compliance in patients with mild essential hypertension. Blood Press. 1999;8:214-219.

15 Schieffer B, Schieffer E, Hilfiker-Kleiner D, et al. Expression of angiotensin II and interleukin 6 in human coronary atherosclerotic plaques: potential implications for inflammation and plaque instability. Circulation. 2000;101:1372-1378.

16 Krämer C, Sunkomat J, Witte J, et al. Angiotensin II receptor-independent antiinflammatory and antiaggregatory properties of losartan: role of the active metabolite EXP3179. Circ Res. 2002;90:770-776.

17 Spence JD. Ultrasound measurement of carotid plaque as a surrogate outcome for coronary artery disease. Am J Cardiol. 2002;89(4A):10B-16B. 